\section{OSTEOMALACIA IN KASHMIR.}

BY

KATHLEEN VAUGHAN, M.B.LOND., LATE SUPERINTENDENT, ZENANA STATE HOSPITAL, SRINAGAR.

Osteomalacia is extremely common in Kashmir. I was for nearly three years medical superintendent of the Maharajah's Zenana Hospital in Srinagar, the chief city, and out of twenty-nine Caesarean sections performed by me during my first year there at least twenty-five were due to pelvic deformity caused by osteomalacia. Of the total 120 midwifery cases admitted to hospital in the year none presented themselves until they had had all the advice available at home, and, with the exception of two, after rupture of the membranes. The number of Caesarean operations increases yearly in Srinagar as the women gain confidence in the hospitals, and their relations take a larger proportion of them for relief rather than allow them to die at home, which was formerly their fate.

Almost all Kashmiri women who have borne children are affected in some degree, with the exception of the manji (boatman) class. Dr. Ernest Neve, who has worked in Kashmir for over twenty-five years, tells me that he does not remember having seen a case of osteomalacia among the boat women, and I too have never seen a case among them. These women live in the open air on the large boats used for carrying rice, wood, etc., on the great Kashmir highway, the Jhelum river; and besides the men, women, and chi!dren, fowls, goats, and sometimes a cow with her calf, are on board. 'These women work hard, and feed with the men. They are too poor to cook their food much, and eat raw cucumber, tomatoes, etc., with their rice, which they husk by hand. They pole and paddle the boats like the men, and are out in all weathers. Their milk supply is provided by their goat or cow, and one may be fairly certain it is not boiled, but consumed as soon as drawn. The disease is unknown among men in any part of the world, and Kashmir is no exception.

The ordinary Kashmiri woman who lives on land, especially the city dwellers, have the disease-sometimes slightly, when there is tenderness of the pelvic bones and the antero-posterior curve of the sacrum is exaggerated, or so acutely that the sufferers can only crawl by means of their arms and legs, the legs being flexed at the knees and the knees drawn up to the shoulders. The worst cases are seen in the houses of the wealthy, who keep their women in seclusion, and among those of the poorer classes who do the same.

There is a marked seasonal incidence; the disease is worse in winter and early spring, during and after confinement to the house in the cold weather, and improves markedly during summer and autumn. A common history is that of confinement to the house at 8 or 9 years of age, marriage at 10 or 11 , menstruation at 12 or 13 , and close confinement in the husband's house until after the first child is born; in the most high-class families the women hardly leave the house till they die. The ordinary woman has more freedom, and when she has borne two or three children she goes out with other women.

Anaemia and debility characterize pregnancy, with vague pains in the ribs, back, and legs, increasing until walking is difficult or impossible at term. The earliest pains complained of are in the lower ribs, about the centre of the bone, and tenderness on vaginal examination may be the first complaint to arouse suspicion of the disease; the pain on pressure is found to be at some spot on the bony wall, not at the symphysis. Backache is a constant complaint, as it is with many pregnant women, but the typical pelvic deformity eventually produced in an acute case which has been going on for years is the tri-radiate pelvis, the pubic bones being pressed together and giving the familiar rostrated appearance - the acetabula pressed in towards one another, the sacrum tilted forward, and the coccyx bent forward; the sacral curve is then more concave than normal, and the foetus at full term may rest on a bony shelf formed by the crumpled-up bones of the maternal pelvis. The following are sample measurements :

Mohammedan, aged 30; purdah, married two years before menstruation began: Interspinous $16 \mathrm{~cm}$., intercristal $19 \mathrm{~cm}$., intertrochanteric $18 \mathrm{~cm}$., external conjugate $15 \mathrm{~cm}$., bi-ischial $5 \mathrm{~cm}$.

A woman aged 28; purdah on marriage two years before menstruation began; her mother also suffered from osteomalacia: Interspinous $17 \frac{1}{2} \mathrm{~cm}$., intercristal $22 \mathrm{~cm}$., intertrochanteric $23 \frac{1}{2} \mathrm{~cm}$., external conjugate $17 \mathrm{~cm}$., bi-ischial $4 \mathrm{~cm}$.

In a few of our cases it was difficult, if not impossible, to reach the os or rupture the membranes; in others the pubic rami were so close together that a finger could with difficulty be inserted sideways. 'Tetany is a common accompaniment of osteomalacia; women are brought to the hospital with their thumbs flexed in the palms of their hands and the whole hand flexed at the wrist. It is not a hysterical manifestation, as experience shows its close connexion with osteomalacia and probably with thyroid and parathyroid deficiency. In many of these cases the thyroid is smaller than normal, and the neck seems wasted on inspection.

Toothache is a common complaint, and pyorrhoea is often present; but the most obvious symptoms are the pains in the bones, in the ribs, pelvis, and the shafts of the long bones, especially the tibia and ulna, which are tender on pressure about the centre. No tenderness or change is to be observed at the joints. The epiphyseal lines seem to me quite unaffected, thus differentiating the condition from rickets.

There may be improvement after confinement, and when lactation ceases. Lactation only ceases when the child dies, otherwise it is continued for from two to four years, and the osteomalacia becomes more acute when the woman again becomes pregnant Many when pregnant are suckling one or two previous children. A man in Srinagar once said to me: "The reason $I$ am so small is that when I was a baby my elder brotiner took all my mother's milk because he was a strong boy; and then my mother had another baby and gave her milk to him, so I got none "a common history.

Tho acuto pains are usually better after delivery, but recur in the second and later pregnancies. The third confinement results in more crippling, and by the fifth month the patient cannot sit or stand or walk without severe pain. She gets up from the ground or from a chair by pressing her hands on her legs as she straightens them and the feet are turned in to keep the balance. This is the and the fect are turned in to keep treet in walking behind such a woman, who looks as if she was going to fall over her big toes, and the gait has a well marked waddling character. Many suffer from phthisis and tuberculous glands, and many of the men of the families in which there is osteomalacia suffer from tuberculosis. It is too constant a relationship to be mere chance.

Anaemia is always present, and unfortunately is admired, as a fair complexion is considered a sign of being well bred. The Kashmiri of pure Aryan parentage is fair, and some of the men carry umbrellas to guard their complexions from the sun. The pale hue so much sought after is increased by the seclusion of the women, not only from the outside world but from sun and air. The better-class women when they go out wear, from the age of 10 , a "burka" - c cloak covering the head and body, with two lattice-work holes for the eyes.

Palpitution and breathlessness, the usual accompaniments of anaemia, are present, and a dilated heart is not uncommoil. In a well marked case the pulse is always rapid, and may rise to 120 or 140 on the least exertion.

The temperature is not raised. Oral sepsis, indigestion, and intestinal worms are common.

Some apparently impossible midwifery cases, terminate spontaneously after several days in labour-provided, of course, the deformity is not such as to prevent the head engaging in the superior strait of the pelvis; the pressure of the liead may be sufficient to make the softened bones yield, but as the woman gets older the bones ossify in faulty positions and the crumpled pelvis becomes unvielding.

Many deaths take place in childbirth owing to conditions cunsequent upon osteomalacia, and as skilled 
assistance is not available mother and child are often lost. The native midwife, who has no training but tradition (the trade is hereditary), performs a rough craniotomy with the sharp end of a spindle, removes the infant's brains, places a loop of string round the neck, and extracts. In a difficult case she may pierce the mother's uterus, and the mother frequently dies of septicaemia. A native midwife will "clean" her hands before making an examination by rubbing them on the mud floor. She frequently completes her attentions to the patient by rubbing salt or mustard oil into the lacerated vagina. Atresia of the vagina caused by such measures is fairly common. A natural cure of the pains and softness of the bones occurs at the menopause.

One of the most remarkable things where Caesarean section is done for these women is the size and healthiness of the child. The women are thin, anaemic, and deformed; their offspring at birth are often extremely fine, healthy; lieavy specimens, and later show no sign of rickets. All the mothers suckle their offspring. Rickets is not common in Kashmir. The few cases I have seen were in female children who had lost their mothers in infancy, belonged to wealthy Kashmiri families, and had been kept indoors with the women. Usually even infants go out, and male infants are taken out by the men and boys to show to their friends when very young. A girl child is never made so much of.

There are three indigenous Kashmiri cures for " troublo in the bones": (1) a special clay called baramulla earth; (2) pills made of fish liver; (3) rubbing with mustard oil and exposing to sunlight.

1. Baramulla earth is a greyish-white fire-clay used for making fireplaces in wooden boats, and for portable fire-pots on which to cook food. A lump of this earth taken from a patient with osteomalacia, who ate pieces of it, was analysed for me by the Clinical Research Association, which reported that it was a ferruginous clay containing a fairly high percentage of calcium phosphate (calcium phosphate 16.2 per cent., ferric oxide 11.8 per cent., hydrated aluminium silicate (in clay) 71.2 per cent., and undetermined residue 0.8 per cent.). Sulphates were present to a very small extent. The radio-activity of the sample was not more than is usually found in any natural earth arsenic and similar metals were not detected.

2. The fish-liver pills are sold by a Panditani (Hindu woman) living at the city fish market. She makes them herself. The analogy with cod-liver oil is interesting.

3. The mustard oil and sunlight cure is chiefly used by the men for their rheumatic pains.

At the Zenana Hospital we prescribed cod-liver oil and phosphorus oil in 3-minim doses, and considered it did good. Calcium lactate in 10-grain doses seemed to slow the heart and relieve the pains in acute cases. Hypodermic injections of sodium morrhuate seemed to give good results, but wo found that the one patient cured had been sitting in the sun all day in order to get tea from the kitchen. I am inclined to think the same of cases said to improve when admitted to hospital, as the light in the wards is better than anything they have at home. Out-patients given cod-liver oil and ordered to go out on the lake in open boats improved rapidly.

Good results have been reported from excision or resec tion of the ovaries. It must, however, be remembered that once a woman ceases to menstruate she is no longer guarded with the same care, and will have more chance to go out in the sun. This may account for the marked improvement at the menopause seen in all cases.

Various theories have been put forward as regards this disease and its frequency in Kashmir.

\section{Diet.}

The richer classes cook all their food. The milk is boiled and reboiled. The city dwellers who keep their own cows have them in dark stables or in the courtyard and send them out daily to graze. In some cases they are fed on dry food and rarely go out. Sheep and goat's milk is used, generally when prescribed as medicine by the Kashmiri practitioner. Vegetable oil, either mustard or sesamum, is used for cooking. The oil is heated to boiling point first. The women eat no raw regetable or fruit; they think anything uncooked un- wholesome, and in a place decimated by cholera every few years it probably is. The rich eat rice husked by machinery, which removes the pink pericarp and the germ. The bran which is thus produced is given to the cattle, and is, of course, rich in phosphates. The women eat after the men, and therefore get less meat and milk, both considered luxuries, but otherwise their diet is the same as that of their menfolk.

The drinking water in the city comes from two sourcesthe river Jhelum and the tap water. The tap supply is often contaminated by the breaking of the lids of the wooden troughs which convey it to the city from a valley three or four miles away. When broken the nearest inhabitants drink and wash themselves at the break, so that last year warning had to be given to consumers that the water should be boiled before use as it was probably infected with cholera. Both rich and poor drink water, but tea is the favourite beverage for all. The better kinds come from Tibet in bricks, from which shavings are made and boiled up with salt and spices.

The natural supply from the river is preferred by the most religious, as the water of the Jhelum is sacred. The river is also the natural sewer of the town. One encounters corpses in it-from those of rats and fowls to thosc of drowned sheep and cattle, bodies of unwanted babies, and of persons drowned by accident. In addition to this the Hindus attend to the calls of Nature, wash themselves, and drink of its waters at the steps leading to it, and the Mohammedans have boxes in the stream for washing and sanitary needs. Persons may thus be seen drinking water from the river a yard or two lower down from those passing their urine and faeces into the same stream. The water of the river is considered so sacred that it cannot be defiled. It can hardly be matter for surprise that everyone suffers from intestinal worms. Large round white ones are the commonest, and their leaving the body is often a sign of the impending death of a patient, as a housesurgeon with long Indian experience once pointed out to me.

\section{Social Customs.}

Purdah, which means a curtain, is used of the system which ensures the seclusion of the woman from all men except her husband and her brothers. It varies in strictness, and is much less strict in Kashmir than in India. In Kashmir it really only affects the women of marriageable and childbearing age. Among the better classes they are more or less confined to the house.

Girls of 8 are not allowed out alone, and if brought to hospital are often closely veiled. The Hindus, who in theory do not observe this custom, do so in practice. The young girls from 8 or 10 to 15 rarely go out until married, and then not till after the birth of one or two children. Marriage takes place before puberty in many cases, because in order to ensure early marriage the younger the bride the less are the fees to the priests. One of the greatest sins a father can commit is not to have married his daughter at puberty. After marriage she is confined to her husband's house, and her food and happiness depend entirely upon her mother-in-law, who often keeps her short of food, from an idea that she will have an easier confirement if the foetus is kept small by spare diet. It has been pointed out by other observers that much tuberculosis originates in these girls during the first year of married life owing to these miserable conditions.

At childbirth the woman is confined in a dark unventilated room, often with no window at all, no fireplace, but a charcoal brazier or the fire basket. Forty dars is not an uncommon time for the young mother to be in this unventilated place, and she emerges weak and ill, Osteomalacia usually begins with the first pregnancy or soon after marriage.

Heredity.-Mothers with old osteomalacia will bring daughters or daughters-in-law to hospital, and are anxious to say that the disease is not in their family, but is hereditary in some other family with whom marriages have been made. One finds they belong to one social casto whose rules require seclusion of girls from 8 or 10 years of age until after marriage and when they have borne several children. 
Climatic Conditions.

Kashmir lies between $32^{\circ}$ and $36^{\circ}$ latitude, and is roughly at the same distance from the equator as Southern Spain or Morocco. The city of Srinagar lies in the valley through which the River Jhelum flows, and the town is built on each side of the river. The valley lies at an altitude of 5,000 feet. The hills round this valley are 7,000 or 8,000 feet in height; further away are hills of 12,000 to 13,000 feet, and still higher peaks overtop these in the distance.

All English flowers and fruit grow well. The temperature may rise to $90^{\circ}$ or over in the hottest days of July and August; and again in winter the thermometer falls $10^{\circ}$ and more below zero; yet on the whole it is a temperate and equable climate for eight months of the year. In the winter months osteomalacia becomes much worse. Wood is the fuel burnt, and during the four winter months a thick pall of fog and smoke hangs over the city in the early morning and evening.

The streets leading from the river are narrow and tortuous, and the houses, which are of wood, are high and built round small courtyards, wherre in the winter the sun never shines. Nor does it reach the ground of many of the streets where the aspect faces north. Icicles ten feet and more in length hang for weeks in such places from the roof, and snow to a depth of four or five feet lies in the streets. The roofs have to be cleared of snow or they would give way under the weight; men shovel it off, and it lies in the streets until spring comes. Owing to reflection there is some slight improvement in the light in the dwellings when the snow comes.

The women wear but one garment and go out in the winter as little as possible. They live in the lowest rooms of the high wooden houses in the winter, so as to be on the same floor as the water supply and the fire. The ground floor is the warmest. The windows are sometimes less than half a yard square, and protected against thieves by being near the ceiling and closed by wooden lattice-work. All windows are so made, but on the upper floors are larger. In winter they are covered with oiled paper to keep out the cold. The minimum of available light is thus admitted, and some rooms, specially liked for warmth, have no windows at all

That the light supply is sufficient for health in all ordinary life is proved by the rarity of rickets and the healthiness of the boat women and the country women working in the fields, but a degree of seclusion which would hare little effect on the plains of India produces osteomalacia in Kashmir. A photographer who lived for many years in Kashmir said that he always gave twice the exposure he would in England to get a good result in Kashmir, which looks as if the actinic rays might bo deficient. Most of the oblique rays of the sun in midwinter are cut off by the mountains encircling the valley.

Sunlight alone can cure the disease, and cod-liver oil without sunshine is of very little use. The seasonal incidence above described points to the same cause-absence of sunlight. In spring and summer the women go out and improve in health. The disease only occurs in those deprived of sunlight, and one meets women walking about who have evidently had the disease, and who will tell you they were shut up as young women, but on the death of the husband wero free to go out. One woman told me she only began to suffer in her later confinements when her husband had moved from a house facing an open space to the crowded quarters of the city. The fact that the men of the families where the women have osteomalacia are so often tuberculous points to the same thing.

Reports from places in India where cases of osteomalacia occur would indicate lack of sunlight as the cause.

At Islamabad, higher up the valley than Srinagar, the doctor tells me that wherever she goes she sees cases, especially among the wives of priests, shopkeepers, and butchers-all men having some means and able to keep their young wives in seclusion during their early married life. At Ladakh, 11,000 feet, with long cold winters, it is unknown, except for one case in a Kashmiri woman. The women there go out freely. At Peshawar among the Afghan women, who go out freely and live an open-air life, none were known; the only cases reported were in Hindu shopkeepers' wives, who married young and were kept in purdah. In Lahore the disease is uncommon; the worst cases occur among those who seclude their women and are rich enough to have glass windows, sometimes made so that they cannot be opened.

The most instructive notes come from Bombay, where the Parsee women are completely free from it, and yet the women of the weaver class have it, and were they not recruited from the outside country villages would die out in a generation. A Parsee doctor tells me that out of 25,000 deliveries he did not encounter one case of osteomalacia among Parsees. They have great freedom, and do not marry until about 20 or 22 . The weaver class, on the other hand, living in the same town are almost all affected. The superintendent of the Cama hospital tells me they suspect osteomalacia in every weaver woman coming for her confinement. These women live in buildings eight stories high. The loom is on the ground floor in the room facing the street, because all available light is needed for the work, and the women live in dark rooms behind that; the mortality rate is 678 per 1,000 infants under 1 year.

In Chamba, in the Himalayas, the village women do not suffer, but in the hill town there is " hardly any sunlight" in their houses, and those in purdah, the richer women, suffer badly. In Hyderabad the disease is very rare, but cases are known in Hindu women, who eat fuller's earth to cure it.

I also have some notes of the occurrence of the disease in cows in places as distant from one another as Norway, New Zealand, and Australia. I have never seen a case in cattle in Kashmir, but there the cows living in the city are turned out to pick up any garbags they can find in the streets. They thus get any sunlight and air available. In Norway fractures of the bones of affected cattle were reported. Its occurrence in male animals, and its appearance after drought when artificial dry feeding had to be resorted to; the absence of the disease in cows at the sea where they consume fish, and in the extreme north where there is darkness for several montis in winter, are all points of interest. Professor Per Tuff of Aas, Norway, says the disease, which led to fractures of bones, is much less common than it was fifty years ago, and he attributes this to the better lighting and hrgiene of cattle sheds.

My best thanks are due to those who have so kindly answered my inquiries during the past few years as to the conditions in their districts where osteomalacia occurs either among the women or the cattle.

These rough notes are published in the hope that something may be done in Kashmir to investigate still further the conditions of the sunlight there, with a view to the prevention of this disease, to which the lives of hundreds of women and children are sacrificed every year.

\section{NOTES ON THE USE OF LEAD COLLOIDS $\urcorner$ IN THE TREATMENT OF CANCER. \\ BY \\ FRANK COKE, F.R.C.S., AND}

J. B. COOK, M.D., D.P.H.,

MEDICAL SUPERINTENDENT OF THE WEST MIDDLESEX HOSPITAL.

Tre question of the treatment of cancer by lead is now so much before the profession that our experiences with this metal may be of interest.

For some years past we have independently tested new cancer cures as tiney have appeared in the English and foreign journals. The article by Professor Blair Bell in the Lancet of 1922 (vol. ii, p. 1005) seemed to be of such importance and to stand on such a rational basis as to invite an early trial of the effect of lead on cases of inoperable cancer. As we did not find it possible to obtain information from Dr. Blair Bell beyond that which had appeared in his articles, a convenient source of lead had to be secured. The aim has been to find a combination of lead with a suitable radicle, the latter, if possible, assisting the absorption or adsorption of the lead. One of the chief difficulties was to obtain a colloidal suspension of the 